\title{
Hydrofluoric acid concentration, time and use of phosphoric acid on the bond strength of feldspathic ceramics
}

Dayanne Monielle Duarte MOURA ${ }^{(a)}$

Arthur Magno Medeiros de ARAÚJO(b)

Karina Barbosa de SOUZA(a)

Aretha Heitor VERÍSSIMO(a)

João Paulo Mendes TRIBST ${ }^{(c)}$

Rodrigo Othávio de Assunção e SOUZA(a)

(a) Universidade Federal do Rio Grande do Norte - UFRN, Department of Dentistry, Natal, RN, Brazil.

(b) Universidadade Federal do Paraná - UFPR, Clinical Hospital, Curitiba, PR, Brazil.

(c) Universidade Estadual de São Paulo Unesp, DDs, Institute of Science and Technology, Department of Dental Materials and Prosthodontics, São José dos Campos, SP, Brazil.

Declaration of Interests: The authors certify that they have no commercial or associative interest that represents a conflict of interest in connection with the manuscript.

\section{Corresponding Author:}

Rodrigo Othávio de Assunção e Souza

E-mail: rodrigoothavio@gmail.com

hitps://doi.org/10.1590/1807-3107bor-2020.vol34.0018

Submitted: August 13, 2019

Accepted for publication: January 6, 2020

Last revision: January 23, 2020
Abstract: The objective of this study was to evaluate the influence of hydrofluoric acid (HF) concentration, etching time, and application of phosphoric acid (PA) followed by neutralization with sodium bicarbonate on the bond strength between a feldspar ceramic and resin cement. Thus, 80 blocks $(10 \times 12 \times 2 \mathrm{~mm})$ of glass ceramic (VM Vita Mark II - Vita Zahnfabrik) were made and randomly assigned to eight groups ( $\mathrm{n}=10)$ according to the factors: HF concentration (5 and $10 \%$ ), etching time (60 and $120 \mathrm{~s}$ ), and use of phosphoric acid (PA) (with and without). According to the experimental group, 37\% PA (Condac, FGM) was applied after HF etching for 60s. Afterwards, samples were immersed in sodium bicarbonate for $1 \mathrm{~min}$ then in an ultrasonic bath in distilled water ( $5 \mathrm{~min}$ ) for cleaning. After surface bonding treatment, cylinders $(\varnothing=2 \mathrm{~mm}$; h $=2 \mathrm{~mm}$ ) of dual resin cement (AllCem / FGM) were made in the center of each block. The samples were then stored in water $\left(37^{\circ} \mathrm{C}\right)$ for 90 days and submitted to the shear bond test $(50 \mathrm{KgF}$, $1 \mathrm{~mm} / \mathrm{min}$ ). Failure analysis was performed by stereomicroscope and scanning electron microscopy. Data (MPa) were analyzed with 3-way ANOVA and Tukey's test. Only the factor "HF concentration" was significant $(p=0.02)$. Most failures were of cohesive in ceramic $(40 \%)$ and mixed types (42.5\%). The 10\% HF resulted in higher shear bond strength value than the $5 \%$ HF. Surface cleaning with phosphoric acid followed by sodium bicarbonate and HF time (60 or 120 seconds) did not influence the resin bond strength to feldspar ceramic.

Keywords: Hydrofluoric Acid; Ceramics; Shear Strength.

\section{Introduction}

Glass-based dental ceramics have excellent aesthetic and mechanical properties in addition to biocompatibility and thus have broad clinical application for onlays, inlays, ${ }^{1}$ veneers,${ }^{2}$ and crowns. ${ }^{3}$ Among commonly used ceramics for dental restorations, feldspar ceramics have a reported longevity of $90.4 \%$ in 10 years for onlays and inlays ${ }^{1}$ and 94.7 to $95 \%$ in 12 years for posterior crowns. ${ }^{4}$ However, clinical problems have been reported, such as caries in crown margins, cervical faults, fractures, and restoration detachment. ${ }^{5}$

For adequate adhesion of feldspar ceramics, the surface treatment of these ceramics with hydrofluoric acid (HF) is a well-accepted method ${ }^{6,7}$ as 
the acid dissolves the ceramic glass matrix, increasing free energy and surface porosity, and providing greater surface area for adhesion to resinous compounds. ${ }^{6,7}$ HF etching also exposes hydroxyl groups that are important for chemical bonding through coupling agents present in silane. ${ }^{8}$ However, $\mathrm{HF}$ concentration and etching time may influence the size and shape of micro-retentions, and consequently, the bond strength with the substrate. ${ }^{9,10}$ In addition, depending on acid exposure and concentration, the mechanical properties of ceramics may be negatively affected, causing decreased fatigue and flexural strength, and surface changes, which could increase the risk of fractures, especially if mechanical imbrication with the resin cement is incomplete. ${ }^{11,12}$

Venturine et al. ${ }^{13}$ evaluated the effect of different HF concentrations on the durability of the bond strength to feldspar ceramic and found that etching with 3,5 , and $10 \%$ HF promoted stable adhesion to resin compounds after aging. Moreover, Naves et al. ${ }^{6}$ evaluated the effect of different acid etching times $(10,20,40,60$ and 120 seconds) with $10 \%$ HF on the adhesion of ceramic, observing that bond strength decreased with increasing etching time. The acid etching causes the precipitation of silica and fluoride salts, ${ }^{14}$ which can be trapped in the micro retentions, affecting the bond strength. This seems to be a great problem of acid treatments and the use of agents to remove these residues have been suggested; ${ }^{15,16}$ however, other authors have reported that the presence of residues do not significantly reduce the resin bond strength. ${ }^{17,18}$

To overcome these limitations and optimize adhesion between feldspar ceramics and resin cements, cleaning procedures (application of 37\% phosphoric acid/PA, ${ }^{18}$ air/water spray, ${ }_{1}^{18}$ ultrasonic bath, ${ }^{19}$ and basic salt neutralizing agents (Neutralizing Powder ${ }^{\hat{a}}$ ) Ivoclar) ${ }^{20}$ or their combination after HF treatment has been investigated. However, some authors also highlight the toxicity of $\mathrm{HF}$ as a reason for using neutralizing agents, but these products may decrease the resin bond strength to ceramics. ${ }^{19,20}$

Therefore, considering that 37\% PA, air-water spray, ultrasonic bath and sodium bicarbonate solution are the techniques most commonly used by dentists, the present study aimed to evaluate the influence of HF concentration, etching time, and 37\% PA application followed by neutralization with sodium bicarbonate on the bond strength between a feldspathic ceramic and a resin cement. The hypotheses tested were: a) higher HF concentration leads to higher bond strength, b) longer etching time promotes higher bond strength, and c) PA application followed by neutralization with sodium bicarbonate improves the bond strength.

\section{Methodology}

Product name, composition, manufacturers, and batch number of the materials used in this study are presented in Table 1.

\section{Ceramic blocks fabrication}

Ceramic blocks $(10 \times 12 \times 15$ mm, Vita Mark II Vita Zahnfabrik, Säckingen, Germany) were sectioned with a double-sided diamond disc (Microdont; São Paulo, Brazil, No. 34.570) mounted on a straight hand piece micro-motor (LB100 Beltec, São Paulo, Brazil) under air/water irrigation to produce eighty smaller ceramic blocks of $10 \times 12 \times 2 \mathrm{~mm}$ measured with a digital caliper (Eccofer, Curitiba, Brazil). The blocks were then polished by sanding with a sequence of sandpapers (\# 600, 800, 1000, and 1200 - 3M, St.Paul, USA).

\section{Embedding of blocks}

The eighty blocks were embedded in chemically activated acrylic resin (JET, Classic Dental Articles, Campo Limpo Paulista, Brazil) using a silicone mold (Master-Talmax silicone, Curitiba, Brazil). After polymerization of the acrylic resin, the surface of the ceramic blocks was polished with sandpaper (\# 600, \# 800, \# 1,000 and \# 1,200) on a polishing machine (Labpol 8-12, Extec, Enfield, USA). The blocks were randomly distributed in eight groups $(n=10)$ according to the factors "HF concentration" (5 and 10\%), "HF etching time" (60 and 120 s) and "PA treatment (with or without), as shown in Figure 1.

\section{Surface treatments}

Prior to each surface treatment procedures, all ceramic blocks were immersed in distilled water and 
Table 1. Information of the materials used in this study.

\begin{tabular}{|c|c|c|c|c|}
\hline Product & Material type & Chemical composition & Batch No. & Manufacturer \\
\hline Vita Blocs Mark II & Feldspathic Ceramic & $\begin{array}{l}\text { Feldspathic crystal particles embedded in a glass } \\
\text { matrix Vol } \% \approx 30\end{array}$ & 15670 & $\begin{array}{l}\text { VITA Zahnfabrik, Bad } \\
\text { Säckingen, Germany }\end{array}$ \\
\hline $\begin{array}{l}\text { Condac porcelana } \\
(5 \% \text { and } 10 \%)\end{array}$ & Hydrofluoric acid & $\begin{array}{c}5 \% \text { or } 10 \% \text { hydrofluoric acid, water, thickener, } \\
\text { surfactant, and pigment }\end{array}$ & $\begin{array}{l}50815 \text { and } \\
120815\end{array}$ & $\begin{array}{l}\text { FGM; Joinville, SC, } \\
\text { Brasil }\end{array}$ \\
\hline Condac 37\% & Phosphoric acid & $\begin{array}{c}37 \% \text { phosphoric acid, thickener, pigment and } \\
\text { deionized water. }\end{array}$ & - & FGM \\
\hline Prosil & Silane & $\begin{array}{c}\text { 3-Methacryloxypropyltrimethoxysilane, ethanol, } \\
\text { and water. }\end{array}$ & 40815 & $\begin{array}{l}\text { FGM; Joinville, SC, } \\
\text { Brasil }\end{array}$ \\
\hline Ambar & Adhesive system & $\begin{array}{c}\text { UDMA, HEMA methacrylic acid, methacrylate } \\
\text { hydrophilic monomers, ethanol, water, silica } \\
\text { nanoparticles, light-initiators, co-initiators, } \\
\text { and stabilizers }\end{array}$ & 230615 & $\begin{array}{c}\text { FGM; Joinville, SC, } \\
\text { Brasil }\end{array}$ \\
\hline Allcem Dual & $\begin{array}{l}\text { Dual conventional } \\
\text { resin cement }\end{array}$ & $\begin{array}{l}\text { Initiators (camphorquinone and di-benzoyl } \\
\text { peroxide), stabilizers, barium-silicate glass } \\
\text { microparticles, and silicon dioxide microparticles, } \\
\text { and silicon dioxide nanoparticles }\end{array}$ & 200815 & $\begin{array}{c}\text { FGM; Joinville, SC, } \\
\text { Brasil }\end{array}$ \\
\hline
\end{tabular}

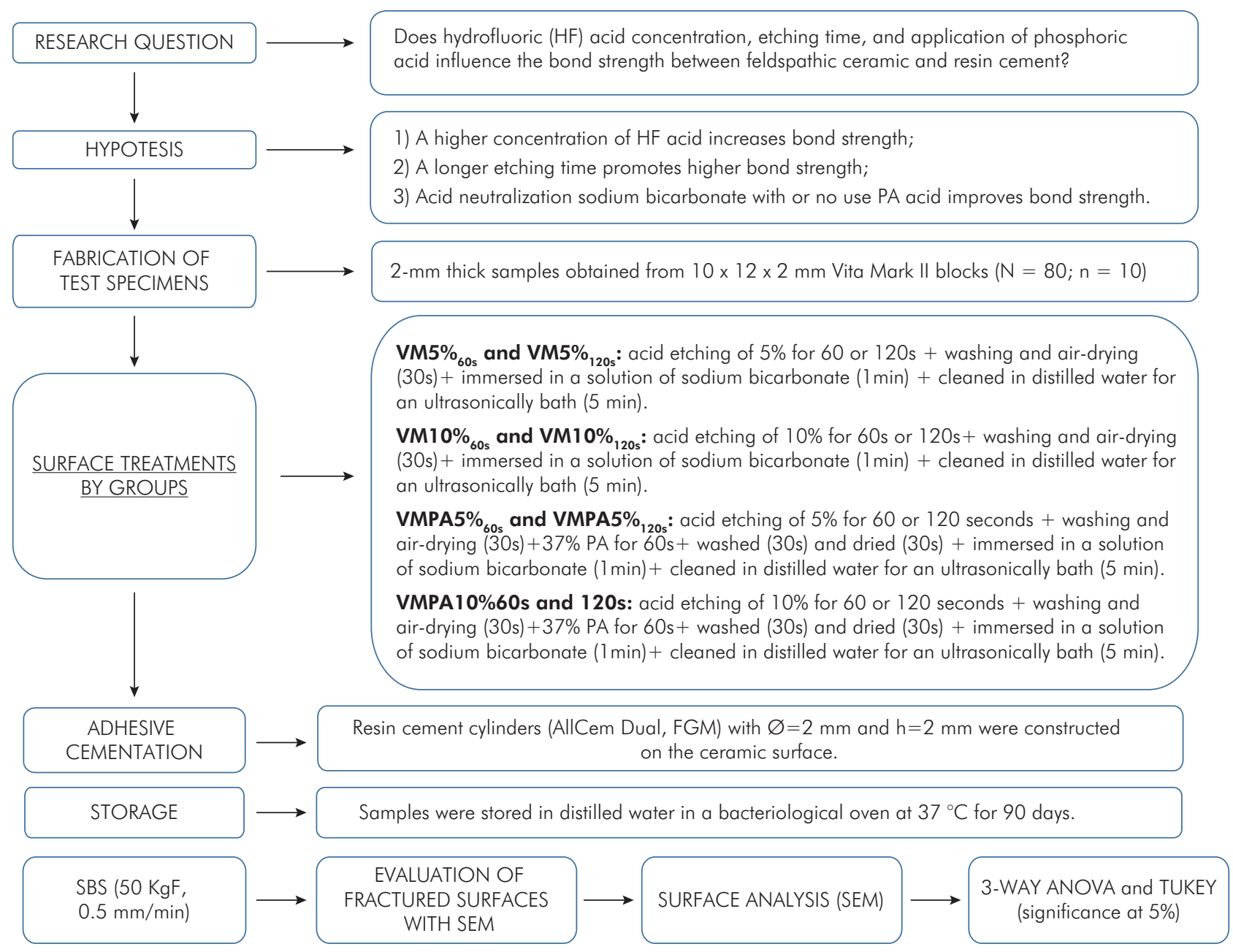

Figure 1. Study flowchart with experimental groups according to the factors: "Phosphoric acid - PA" - 2 degrees: (with acid: PA and without acid) and "HF concentration" (2 degrees: 5\% and 10\%) and "Exposure time": (2 levels: HF60s; HF120s) and general information of the methodology. VM: VITA MARK II CERAMIC BLOCKS. * $n=80$ and $n=10$. 
cleaned in an ultrasonic device for 5 min (Cristófoli Equipamentos de Biosecurity LTDA, Campo Mourão, Brazil) then left to dry for about $10 \mathrm{~min}$. An adhesive area was delimited by placing on the block surface an adhesive tape (Scotch, 3M, Ribeirão Preto, Brazil) with a perforation of $3 \mathrm{~mm}$ in diameter.

HF (5 or 10\%, Prosil, FGM, Joinville, SC, Brazil) was applied to the delimited area with a microbrush (Dentsply, New York, USA). According to the group, the acid was left for 60 or 120 seconds before washing with air/water spray for 30 seconds and air-drying for 30 seconds. After HF etching, the ceramic surfaces were washed and air-dried, and 37\% PA (Condac, FGM, Joinville, Brazil) was applied on half of the blocks with a microbrush for 60 seconds and then the surface was washed and dried as previously described. Prior to the application of silane, all samples were immersed in a neutralizing solution of sodium bicarbonate (Biodinâmica, Ibiporã, Brazil). The solution of sodium bicarbonate was prepared by dissolving $50 \mathrm{~g}$ in $250 \mathrm{~mL}$ of water in a glass container. Then, all samples were immersed in this solution for one minute. Afterwards, the samples were cleaned in distilled water in an ultrasonically bath (5 min), and then air-dried.

After surface treatment, a layer of silane (Prosil, FGM; Joinville, Brazil) was applied to all samples with a microbrush (Dentsply, New York, USA) and allowed to dry for 2 minutes. Afterwards, the adhesive system (Ambar, FGM, Joinville, Brazil) was applied and light cured for 20 seconds $\left(1,200 \mathrm{~mW} / \mathrm{cm}^{2}\right.$ Radii Cal, SDI, Bayswater, Australia). The surface treatments descriptions are presented in Figure 1.

\section{Adhesive cementation}

Next, a resin cement cylinder (AllCem Dual, FGM; Joinville, Brazil) was constructed on the ceramic surface. To standardize the size of the cylinders, a Teflon matrix $(\varnothing=2 \mathrm{~mm}$ and $\mathrm{h}=2.0 \mathrm{~mm})$ was used (Ultradent Jig, Ultradent, South Jordan, USA). After the matrix adaptation, the base and catalyst pastes of Allcem Dual were mixed, the matrix was filled, and the resin light cured for $40 \mathrm{~s}$ (1,200 mW/cm² - Radii Cal, SDI, Australia). Five minutes were used for chemical cure, then the matrices were removed and the sets (block + resin cement cylinder) were submitted to aging.

\section{Aging and shear bond strength test}

After cementation, all samples were immersed in distilled water and stored in a bacteriological oven at $37^{\circ} \mathrm{C}$ for 90 days, and then submitted to the shear bond strength test in a universal testing machine (Shimadzu, model Autograph AG-X / $300 \mathrm{KN}$, Natal, Brazil). A metal device was used to position the ceramic/cement interface perpendicular to the horizontal plane. A knife-shaped device was positioned in the load cell ( $50 \mathrm{Kgf})$ and moved towards the interface at a constant speed of $1 \mathrm{~mm} / \mathrm{min}$ until fracture occurred.

The bond strength was calculated with the formula: $\mathrm{R}=\mathrm{F} / \mathrm{A}$, where $\mathrm{R}=$ bond strength $(\mathrm{MPa}) ; \mathrm{F}=$ force $(\mathrm{N}) ; \mathrm{A}=$ interface area $\left(\mathrm{mm}^{2}\right)$. $\mathrm{F}$ is the force at failure and is provided by the universal testing machine software. The area is the round adhesive interface, calculated by the following formula: $\mathrm{A}=\Pi \mathrm{r}^{2}$, where $\Pi=3.14$ and $\mathrm{r}=1.0 \mathrm{~mm}$ (radius of the cylinder), which was $3.14 \mathrm{~mm}^{2}$ in our study.

\section{Failure analysis}

The fractured specimens were examined with an optical stereomicroscope (Stereo Discovery V20, Zeiss, Göttingen, Germany) and representative failure types were analyzed by scanning electron microscope (SEM, Inspect S50, FEI, Czech Republic). For SEM analysis, the specimens were gold-sputtered for 80 seconds at $40 \mathrm{~mA}$, creating a 30-nm thick layer. Failure modes were classified as: A) Adhesive at ceramic/cement interface (ADHES cer/cem); B) Cohesive in ceramic (COHES cer); C) Cohesive in cement (COHES cem); and D) Mixed (adhesive at ceramic/cement interface + cohesive in cement).

\section{Qualitative surface topography analysis (SEM)}

Two blocks from each group were examined at 1500x magnification with SEM (Hitachi TM 3000, Tokyo, Japan) to analyze the effect of different HF concentrations and exposure time on the ceramic surface topography. ${ }^{19,21}$ 


\section{Statistical analysis}

The data distribution was evaluated, and 3-way analysis of variance (ANOVA) and Tukey's test (5\%) were used to compare the differences among groups with the software STATISTIX (Analytical Software Inc., version 8.0). The statistical power was calculated using OpenEpi (Open Source Epidemiologic Statistics for Public Health, www.openepi.com) considering a $95 \%$ confidence interval; a power of $99.16 \%$ was found.

\section{Results}

\section{Shear bond strength}

The factor "HF concentration" $(p=0.02)$ and the interactions "PA*Time $(p=0.01)$ ", HF*Time $(p=0.04)$, and "PA*HF"Time $(p=0.004)$ were statistically significant for shear bond strength (Table 2). According to Tukey's test $(\mathrm{p}=0.05)$, considering only the "HF concentration" factor, 10\% HF (12.68 Mpa) ${ }^{\mathrm{A}}$ resulted in higher bond strength value than $5 \% \mathrm{HF}$ $(10.68 \mathrm{Mpa})^{\mathrm{B}}$.

When all groups were analyzed, the $\mathrm{VM} 10 \%_{60 \mathrm{~s}}$ $(15.35 \pm 3.2)^{\mathrm{A}}$ and VMPA $10 \%_{120 \mathrm{~s}}(15.43 \pm 3.4)^{\mathrm{A}}$ showed significantly higher bond strength values than VMHF5\% $\%_{120 \mathrm{~s}}(9.41 \pm 2.8)^{\mathrm{B}}$ and VMPA10\%60s $(8.21 \pm 4.1)^{\mathrm{B}}$, which had the lowest values but were statistically similar to all the other groups (Table 3).

\section{Failure analysis}

A predominance of cohesive in ceramic failures $(40 \%)$ were found, followed by mixed failures (17.5\%). The failure analysis results are shown in Table 4.

Table 2. Results of the 3-way ANOVA for shear bond strength.

\begin{tabular}{lccccc}
\hline Factors & DF & SQ & MS & F & p-value \\
\hline Phosphoric acid (PA) & 1 & 6.94 & 6.94 & 0.49 & 0.487 \\
Hydrofluoric acid (HF) & 1 & 72.71 & 72.71 & 5.09 & $0.02^{*}$ \\
Time & 1 & 0.19 & 0.193 & 0.01 & 0.907 \\
PA*HF & 1 & 25.46 & 26.45 & 1.78 & 0.186 \\
PA*Time & 1 & 180.51 & 180.510 & 12.63 & $0.000^{*}$ \\
HF*Time & 1 & 57.55 & 57.54 & 4.03 & 0.0418 \\
PA*HF*Time & 1 & 116.96 & 116.95 & 8.18 & $0.005^{*}$ \\
Error & 72 & 1028.94 & 14.291 & & \\
Total & 79 & 1489.27 & & & \\
\hline
\end{tabular}

${ }^{*} p$-value < 0.05: statistical significance, DF: degrees of freedom, SQ: sum of squares, MQ: mean square, F: F statistics.

Table 3. Bond strength of groups according to the factors "Phosphoric acid", "HF Concentration" and "Etching Time". Data are reported as means (MPa) and standard deviation.

\begin{tabular}{|c|c|c|c|c|}
\hline Group Name & Phosphoric acid application & HF concentration & Etching time & Bond strength ( $\mathrm{MPa})$ \\
\hline $\mathrm{VM} 5 \%_{60 \mathrm{~s}}$ & No & \multirow{4}{*}{$5 \%$} & \multirow{2}{*}{$60 \mathrm{~s}$} & $11.59 \pm 1.89^{A B}$ \\
\hline VMPA $5 \%_{60 \mathrm{~s}}$ & Yes & & & $11.55 \pm 3.6^{\mathrm{AB}}$ \\
\hline VM5\% ${ }_{120 \mathrm{~s}}$ & No & & \multirow{2}{*}{$120 s$} & $9.41 \pm 2.8^{B}$ \\
\hline VMPA $5 \%_{120 \mathrm{~s}}$ & Yes & & & $10.53 \pm 4.8^{A B}$ \\
\hline VM10\% $\%_{60 s}$ & No & & \multirow{2}{*}{$60 \mathrm{~s}$} & $15.35 \pm 3.2^{\mathrm{A}}$ \\
\hline VMPA $10 \%_{60 \text { s }}$ & Yes & & & $8.21 \pm 4.1^{\mathrm{B}}$ \\
\hline VM10\% ${ }_{120 s}$ & No & $10 \%$ & \multirow{2}{*}{$120 \mathrm{~s}$} & $11.72 \pm 5.2^{\mathrm{AB}}$ \\
\hline VMPA $10 \%_{120 \text { s }}$ & & & & $15.43 \pm 3.4^{\mathrm{A}}$ \\
\hline
\end{tabular}

Different uppercase letters indicate statistically significant differences between groups ( $p$-value $<0.05$ ). 


\section{Qualitative surface topography analysis (SEM)}

When using both the 5 and $10 \% \mathrm{HF}$ concentrations, etching for $120 \mathrm{~s}$ created an irregular and more porous surface than the 60 -s etching. In the $60 \mathrm{~s}$ groups, the surface was more homogeneous. In addition, the higher acid concentration and longer etching time caused further degradation and more surface irregularities in the ceramic. Representative images of the topography analysis are presented in Figure 2.

\section{Discussion}

$\mathrm{HF}$ acid etching followed by silane application has been the main protocol for surface treatment of ceramic

Table 4. Percentage of failure types.

\begin{tabular}{lcc}
\hline Failure type & $\mathrm{n}$ & \% of total samples \\
\hline $\begin{array}{l}\text { Adhesive at ceramic-adhesive } \\
\text { interface }\end{array}$ & 17 & 17.5 \\
Cohesive in cement & 0 & $0 \%$ \\
Cohesive in ceramic & 16 & $4000 \%$ \\
Mixed & 7 & 42.5 \\
\hline
\end{tabular}

restorations. ${ }^{22}$ However, despite the advantages of this adhesive procedure, acid concentration, etching time, ceramic cleaning, and neutralization techniques can change the surface free energy of the ceramic and affect the adhesion to resin cements, compromising the longevity of restorations. ${ }^{23}$ Some previous studies have already investigated the effect of these changes on the ceramic surface. However, most studies use lithium disilicate ceramics or evaluate the effects of these factors individually. Several methods can be used to evaluate the bond strength of resin cements to ceramics, including microtensile, micro shear, and shear bond methods. Although microtensile and microshear tests present a reduced adhesive area providing fewer internal defects in the adhesive area and surface failures ${ }^{16}$, problems associated with cutting the ceramic, in the microtensile test, or difficulties in standardizing the adhesive area, in the microshear test, may induce premature interface failures, reducing the effectiveness of the assay. ${ }^{24}$ Therefore, the shear bond test was used in this study, which, besides being widely used for bond strength evaluations ${ }^{24}$, is easy to perform and has low cost.

According to the present study results, the first hypothesis that higher HF concentration leads to
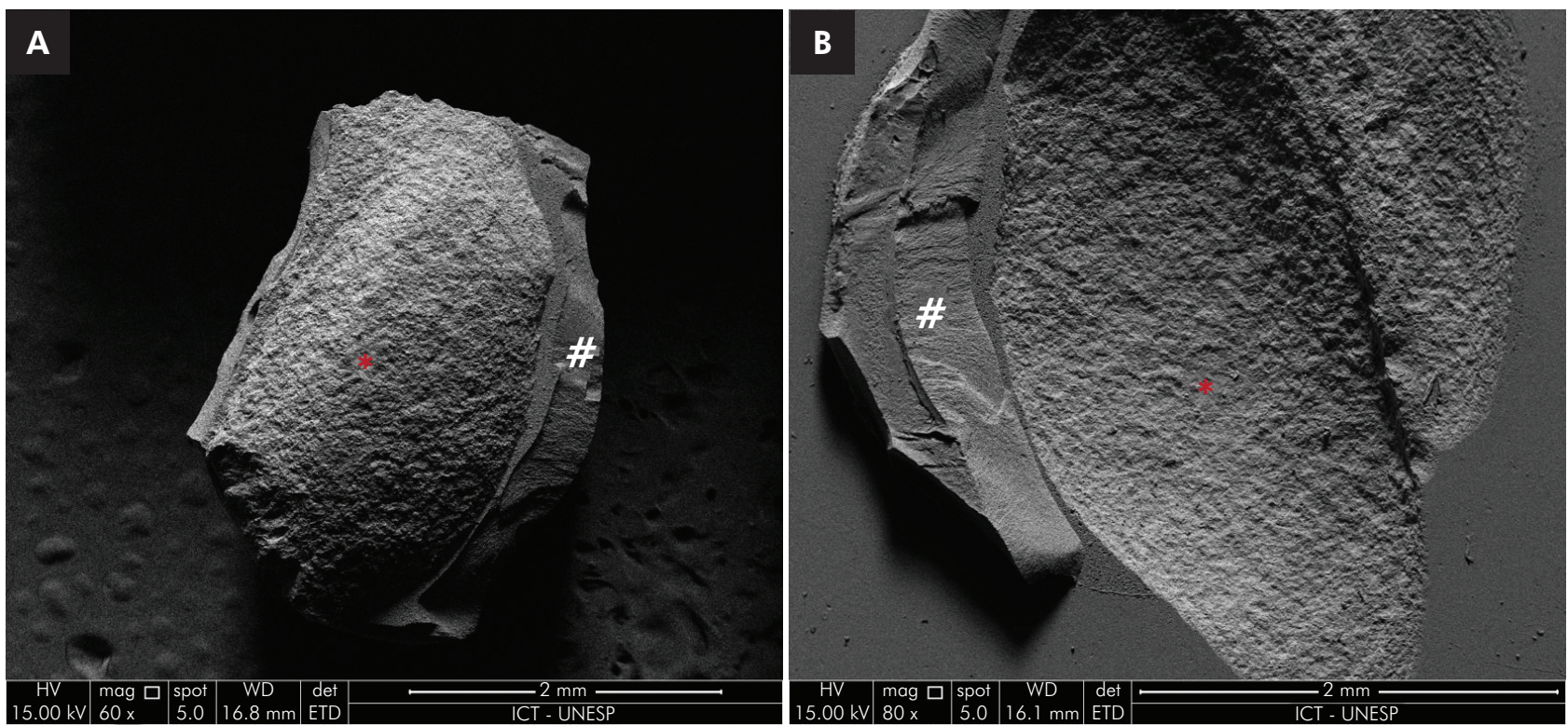

Figure 2. SEM (60x) micrographs of failure modes between the ceramic and resin cement cylinder: mixed failure (A: cohesive in cement, and B: adhesive at ceramic / cement interface). Ceramic (\#), resin cement $(*)$. 

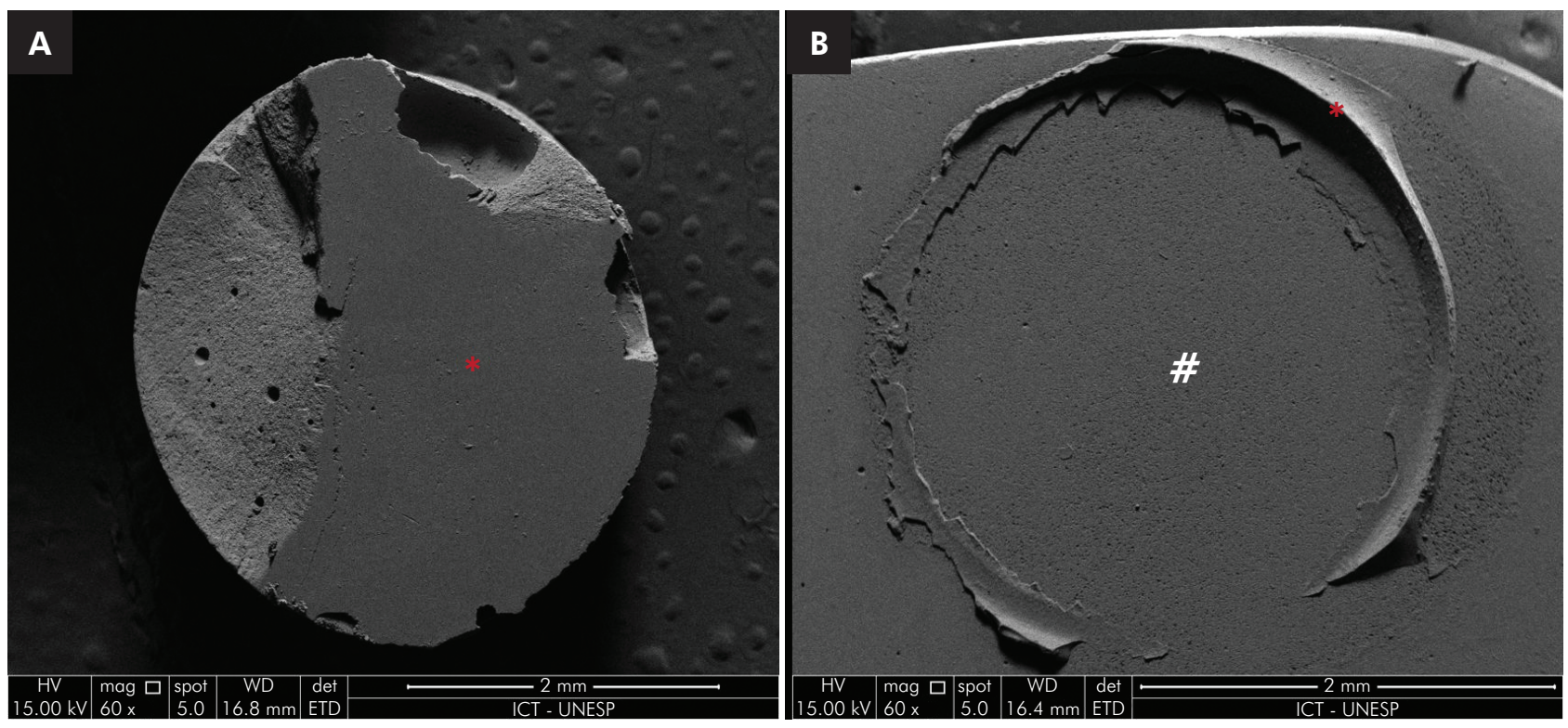

Figure 3. SEM (60x) micrographs of cohesive in ceramic (A) and mixed (A and B) failures. Ceramic $\left({ }^{*}\right)$, resin cement (\#).

increase in bond strength was accepted. The 10\% HF presented higher bond strength than the $5 \% \mathrm{HF}$. Different protocols have been proposed for feldspar ceramics and some studies reported that longer HF etching time, which may vary from 0 to $120 \mathrm{~s}^{25}$ results in higher bond strength values. Different results regarding the ideal etching time and HF concentration have been reported. According to Chen et al. ${ }^{25} 120$-s exposure with $5 \%$ HF provided the highest bond strength for a feldspar ceramic (Vita Mark II. Another study, evaluated different HF acid concentrations $(9,5$, and $4 \%)$ in leucitereinforced feldspathic ceramic, and according to the authors, the HF concentration had no influence on the ceramic bond strength ${ }^{19}$. Other studies ${ }^{26,27}$ evaluated the effect of HF concentrations ( 5 and 10\%) and etching time in feldspar ceramic. According to these authors, the time and the concentration of HF had no influence on the ceramic bond strength as in the results of the present study. The HF concentration and the ideal etching time should be adjusted for each type of ceramic to achieve optimal bond strength. ${ }^{27}$

The second hypothesis that longer etching time (120s) promotes higher bond strength was not accepted. The 20- or 120-s etching time had no influence on bond strength values. A longer etching time, besides increasing roughness and favoring adhesion, can also weaken the biaxial flexural strength, especially in feldspar ceramics. ${ }^{13,21}$ The kinetics between HF and ceramic depends on chemical reactions on the surface, which are affected not only by time and acid concentration, but also by the physical structure of the ceramic. ${ }^{10,28}$ Feldspar ceramics have an amorphous glass matrix consisting of a random network of cross-linked silica tetrahedrons, which have varying amounts of undissolved feldspar. ${ }^{29}$ With exposure to HF, the glass phase is selectively dissolved, increasing the roughness of the ceramic surface, but HF might have a negative effect in flexural strength depending on application time and concentration used. ${ }^{30}$ Therefore, lower acid concentrations and etching for 60 seconds have been suggested. ${ }^{6,13}$ In the present study, the qualitative analysis of surface topography showed that longer etching times (120 s) and a stronger acid concentration (10\%) generated greater degradation of the ceramic matrix, increasing the irregularities and creating deeper microporosities in the surface. As there seems to be no significant difference in bond strength with 60 or 120 s acid etching, a shorter time may be a better option. 

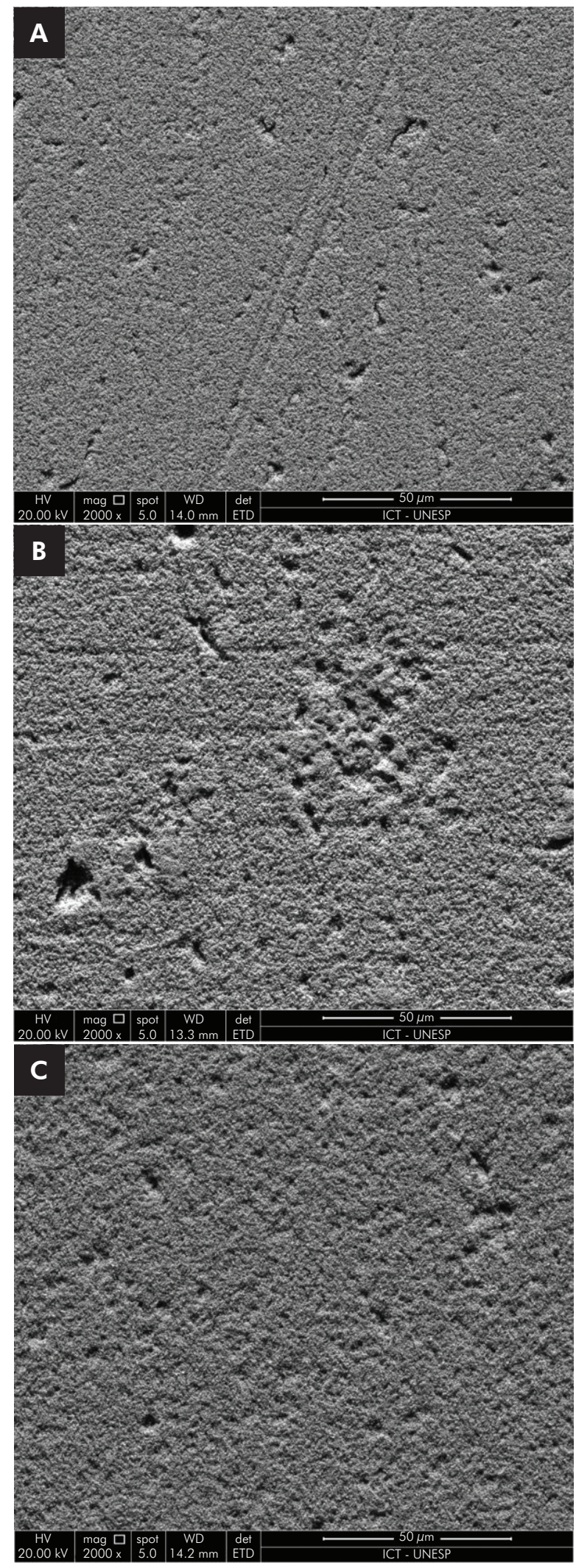

Figure 4. SEM (2000X) micrographs of the ceramic surface with different treatments. A: $5 \%$ HF for 60 s; B: $5 \%$ HF for 120 s; C: $10 \%$ HF for 60 s; D: $10 \%$ HF for 120s;
The third hypothesis of this study that acid neutralization with sodium bicarbonate associated or not with PA improves the bond strength was not accepted. Surface cleaning after HF etching aims to remove residual acid and other contaminants from the etching process. ${ }^{20,31}$ The literature reports that the acid neutralization with a base agent could be an option to reduce the $\mathrm{HF}$ acid risks and toxicity, and eliminate the residual fluoride ion..$^{20}$ Basic salts neutralizing agents (e.g. calcium carbonate/ Neutralizing Powder, Ivoclar) can prevent the toxic effects of $\mathrm{HF}$ acid and neutralize the $\mathrm{pH}$ of a substance from an acid-base reaction by forming water and salt, eliminating HF residues in the pores of the ceramic surface. ${ }^{20,32}$ Considering that sodium bicarbonate is also a basic salt that is easy to find and affordable, it was selected to be used in this study.

The literature does not agrees regarding the cleaning and neutralizing agents that should be used to improve the bond strength. Magne and Cascione ${ }^{33}$ evaluated post-etching cleaning using $37.5 \%$ PA followed by ultrasonic bath on bond strength of feldspar ceramics. According to the authors, the HF precipitates that are not removed from the ceramic surface may decrease adhesion. Saavedra et al. ${ }^{20}$ reported that the use of neutralizing agents after $\mathrm{HF}$ acid etching decreased the bond strength between resin cement and ceramic, concluding that this step is not recommended. Another study ${ }^{34}$ evaluated the effect of neutralizing agents on the shear bond strength of etched (HF) porcelain and according to the authors the treated groups did not differ from the control. That finding corroborates the present study results, in which the cleaning procedure with sodium bicarbonate, associated or not to PA, did not affected the bond strength. The cleaning step can thus be considered unnecessary for the improvement of bonding between cement and feldspathic ceramic.

The failure analysis of our study revealed a greater number of mixed and cohesive ceramic failures. Several factors may be related to these failures, including the mechanical shear test that was used ${ }^{30}$ and the ceramic composition. Some studies report that $\mathrm{HF}$ etching procedures may weaken the surface of feldspar ceramics more than lithium disilicate ceramics, due to the selective dissolution of leucite 
crystal grains and the larger glass phase volume of feldspar ceramics. ${ }^{30,35}$

Further in vitro and clinical studies should investigate the influence of different $\mathrm{HF}$ concentrations, etching times, long thermal aging, and usage of phosphoric acid with other post-etching cleaning methods to determine the durability of the bond between ceramic and resin cement.

\section{Conclusion}

According to the results of this study and within its limitations, HF time (60 or 120 seconds) and surface cleaning with phosphoric acid followed by sodium bicarbonate immersion did not influence the bond strength between feldspar ceramic and resin cement. The 10\% HF resulted in higher shear bond strength than the $5 \% \mathrm{HF}$.

\section{Acknowledgments}

The authors acknowledge the company FGM (Dental products/ Joinville, SC, Brazil) for supplying materials used in the research. This study was financed in part by the Coordenação de Aperfeiçoamento de Pessoal de Nível Superior - Brazil (CAPES) - Finance Code 001".

Note: Part of this study was presented at the $34^{\text {th }}$ meeting of the Brazilian Society of Dental Research (SBPqO - affiliated to IADR) on September 5, 2017, Campinas, São Paulo, Brazil.

\section{References}

1. Otto T, De Nisco S. Computer-aided direct ceramic restorations: a 10-year prospective clinical study of Cerec CAD/CAM inlays and onlays. Int J Prosthodont. 2002 Mar-Apr;15(2):122-8.

2. Tuzzolo Neto H, Nascimento WF, Erly L, Ribeiro RA, Barbosa JS, Zambrana JM, et al. Laminated veneers with stratied feldspathic ceramics. Case Rep Dent. 2018 Dec;(6):ID5368939. https://doi.org/10.1155/2018/5368939

3. Gehrt M, Wolfart S, Rafai N, Reich S, Edelhoff D. Clinical results of lithium-disilicate crowns after up to 9 years of service. Clin Oral Investig. 2013 Jan;17(1):275-84. https://doi.org/10.1007/s00784-012-0700-x

4. Otto T, Mörmann WH. Clinical performance of chairside CAD/CAM feldspathic ceramic posterior shoulder crowns and endocrowns up to 12 years. Int J Comput Dent. 2015;18(2):147-61.

5. Morimoto S, Rebello de Sampaio FB, Braga MM, Sesma N, Özcan M. Survival Rate of Resin and Ceramic Inlays, Onlays, and Overlays: A Systematic Review and Meta-analysis. J Dent Res. 2016 Aug;95(9):985-94. https://doi.org/10.1177/0022034516652848

6. Naves LZ, Soares CJ, Moraes RR, Gonçalves LS, Sinhoreti MA, Correr-Sobrinho L. Surface/interface morphology and bond strength to glass ceramic etched for different periods. Oper Dent. 2010 Jul-Aug;35(4):420-7. https://doi.org/10.2341/09-152-L

7. Soares CJ, Soares PV, Pereira JC, Fonseca RB. Surface treatment protocols in the cementation process of ceramic and laboratory-processed composite restorations: a literature review. J Esthet Restor Dent. 2005;17(4):224-35. https://doi.org/10.1111/j.1708-8240.2005.tb00119.x

8. Ramakrishnaiah R, Alkheraif AA, Divakar DD, Matinlinna JP, Vallittu PK. The Effect of hydrofluoric acid etching duration on the surface micromorphology, roughness, and wettability of dental ceramics. Int J Mol Sci. 2016 May;17(6):E822. https://doi.org/10.3390/ijms17060822

9. Aida M, Hayakawa T, Mizukawa K. Adhesion of composite to porcelain with various surface conditions. J Prosthet Dent. 1995 May;73(5):464-70. https://doi.org/10.1016/S0022-3913(05)80076-9

10. Addison O, Marquis PM, Fleming GJ. The impact of hydrofluoric acid surface treatments on the performance of a porcelain laminate restorative material. Dent Mater. 2007 Apr;23(4):461-8. https://doi.org/10.1016/i.dental.2006.03.002

11. Venturine AB, Prochnow C, Pereira GK, Werner A, Kleverlaan CJ, Valandro LF. The effect of hydrofluoric acid concentration on the fatigue failure load of adhesively cemented feldspathic ceramic discs. Dent Mater. 2007 Apr;23(4):461-8. https://doi.org/10.1016/i.dental.2018.01.010

12. Hooshmand T, Parvizi S, Keshvad A. Effect of surface acid etching on the biaxial flexural strength of two hot-pressed glass ceramics. J Prosthodont. 2008 Jul;17(5):415-9. https://doi.org/10.1111/i.1532-849X.2008.00319.x

13. Venturini AB, Prochnow C, Rambo D, Gundel A, Valandro LF. Effect of hydrofluoric acid concentration on resin adhesion to a feldspathic ceramic. J Adhes Dent. 2015 Aug;17(4):313-20. https://doi.org/10.3290/i.jad.a34592 
Hydrofluoric acid concentration, time and use of phosphoric acid on the bond strength of feldspathic ceramics

14. Fabianelli A, Pollington S, Papacchini F, Goracci C, Cantoro A, Ferrari M, et al. The effect of different surface treatments on bond strength between leucite reinforced feldspathic ceramic and composite resin. J Dent. 2010 Jan;38(1):39-43. https://doi.org/10.1016/j.jdent.2009.08.010

15. Leite F, Özcan M, Valandro LF, Amaral R, Bottino MA, Kimpara ET. Effect of the etching duration and ultrasonic cleaning on microtensile bond strength between feldspathic ceramic and resin cement. J Adhes. 2013 Jul;89(3):159-73. https://doi.org/10.1080/00218464.2013.739024

16. Canay S, Hersek N, Ertan A. Effect of different acid treatments on a porcelain surface. J Oral Rehabil. 2001 Jan;28(1):95-101. https://doi.org/10.1046/i.1365-2842.2001.00626.x

17. Steinhauser HC, Turssi CP, França FM, Amaral FL, Basting RT. Micro-shear bond strength and surface micromorphology of a feldspathic ceramic treated with different cleaning methods after hydrofluoric acid etching. J Appl Oral Sci. 2014 Apr;22(2):85-90. https://doi.org/10.1590/1678-775720130339

18. Belli R, Guimarães JC, Filho AM, Vieira LC. Post-etching cleaning and resin/ceramic bonding: microtensile bond strength and EDX analysis. J Adhes Dent. 2010 Aug;12(4):295-303. https://doi.org/10.3290/i.jad.a17709

19. Bottino MA, Snellaert A, Bergoli CD, Özcan M, Bottino MC, Valandro LF. Effect of ceramic etching protocols on resin bond strength to a feldspar ceramic. Oper Dent. 2015 Mar-Apr;40(2):E40-6. https://doi.org/10.2341/13-344-L

20. Saavedra G, Ariki EK, Federico CD, Galhano G, Zamboni S, Baldissara P, et al. Effect of acid neutralization and mechanical cycling on the microtensile bond strength of glass-ceramic inlays. Oper Dent. 2009 Mar-Apr;34(2):211-6. https://doi.org/10.2341/08-68

21. Veríssimo AH, Moura DM, Tribst JP, Araújo AM, Leite FP, Souza RO. Effect of hydrofluoric acid concentration and etching time on resinbond strength to different glass ceramics. Braz Oral Res. 2019;33:e041. https://doi.org/10.1590/1807-3107bor-2019.vol33.0041

22. D'Arcangelo C, De Angelis F, Vadini M, D'Amario M. Clinical evaluation on porcelain laminate veneers bonded with light-cured composite: results up to 7 years. Clin Oral Investig. 2012 Aug;16(4):1071-9. https://doi.org/10.1007/s00784-011-0593-0

23. Fradeani M, Redemagni M. An 11-year clinical evaluation of leucite-reinforced glass-ceramic crowns: a retrospective study. Quintessence Int. 2002 Jul-Aug;33(7):503-10.

24. Sirisha K, Rambabu T, Shankar YR, Ravikumar P. Validity of bond strength tests: A critical review: Part I. J Conserv Dent. 2014 Jul;17(4):305-11. https://doi.org/10.4103/0972-0707.136340

25. Chen JH, Matsumura H, Atsuta M. Effect of etchant, etching period, and silane priming on bond strength to porcelain of composite resin. Oper Dent. 1998 Sep-Oct;23(5):250-7.

26. Güler AU, Yilmaz F, Yenisey M, Güler E, Ural C. Effect of acid etching time and a self-etching adhesive on the shear bond strength of composite resin to porcelain. J Adhes Dent. 2006 Feb;8(1):21-5.

27. Mokhtarpour F, Alaghehmand $\mathrm{H}$, Khafri S. Effect of hydrofluoric acid surface treatments on micro-shear bond strength of CAD/CAM ceramics. Electron Physician. 2017;25;9(10):5487-93.

28. Mikeska KR, Bennison SJ, Grise SL. Corrosion of ceramics in aqueous hydrofluoric acid. J Prosthet Dent. 2013 Feb;109(2):95-105. https://doi.org/10.1111/i.1151-2916.2000.tb01348.x

29. Della Bona A, Anusavice KJ. Microstructure, composition, and etching topography of dental ceramics. Int J Prosthodont. 2002;15(2):158-67.

30. Addison $O$, Fleming GJ. The influence of cement lute, thermocycling and surface preparation on the strength of a porcelain laminate veneering material. Dent Mater. 2004 Mar;20(3):286-92. https://doi.org/10.1016/S0109-5641(03)00105-2

31. Amaral R, Ozcan M, Bottino MA, Valandro LF. Resin bonding to a feldspar ceramic after different ceramic surface conditioning methods: evaluation of contact angle, surface $\mathrm{pH}$, and microtensile bond strength durability. J Adhes Dent. 2011 Dec;13(6):551-60. https://doi.org/10.3290/i.jad.a19815

32. Özcan M, Volpato CA. Surface conditioning protocol for the adhesion of resin-based materials to glassy matrix ceramics: how to condition and why? J Adhes Dent. 2015 Jun;17(3):292-3. https://doi.org/10.3290/i.jad.a34590

33. Magne P, Cascione D. Influence of post-etching cleaning and connecting porcelain on the microtensile bond strength of composite resin to feldspathic porcelain. J Prosthet Dent. 2006 Nov;96(5):354-61. https://doi.org/10.1016/i.prosdent.2006.09.007

34. Sriamporn T, Kraisintu P, See LP, Swasdison S, Klaisiri A, Thamrongananskul N. Effect of Different neutralizing agents on feldspathic porcelain etched by hydrofluoric acid. Eur J Dent. 2019 Feb;13(1):75-81. https://doi.org/10.1055/s-0039-1688535

35. Melo RM, Valandro LF, Bottino MA. Microtensile bond strength of a repair composite to leucite-reinforced feldspathic ceramic. Braz Dent J. 2007;18(4):314-9. https://doi.org/10.1590/S0103-64402007000400008 